\title{
GUINÉ PORTUGUESA VERSUS GUINÉ-BISSAU: A LUTA DA LIBERTAÇÃO NACIONAL E O PROJETO DE CONSTRUÇÃO DO ESTADO GUINEENSE
}

\author{
Artemisa Odila Candé Monteiro ${ }^{1}$
}

\begin{abstract}
Resumo: Esse texto é parte da minha tese de doutorado, em andamento, que objetiva descrever como os processos de resistências na Guiné Portuguesa (nome atribuído a Guiné-Bissau no quadro da colonização portuguesa, sendo considerado assim o território exclusivo da ultramar portuguesa) se desencadearam, analisando o protagonismo dos seus habitantes; buscamos também desmistificar a concepção de passividade atribuída aos africanos durante os séculos da colonização nesse processo. Ao apresentar essa outra perspectiva, diferente do que se estabeleceu na literatura já existente, ancorada nas distorções eurocêntricas associadas ao passado do colonialismo na história da Guiné-Bissau, este estudo oferece outra perspectiva que busca contar uma História da África a partir da reflexão dos africanos.

Palavras-Chave: Luta de libertação nacional, Resistências étnicas, Identidade guineense, Identidade étnica, Guiné-Bissau.
\end{abstract}

Resumen: El artículo objetiva describir como se desencadenaron los procesos de resistencia en Guinea Portuguesa (nombre que se le dio a Guinea-Bissau en el cuadro de la colonización portuguesa), analizando el protagonismo de sus habitantes. Además se busca desmitificar la concepción de pasividad que se les atribuyó a los africanos a lo largo de la colonización. Al presentarse otra perspectiva, distinta a la que se estableció en la literatura anterior llena de distorsiones eurocéntricas, asociadas al pasado colonialista de GuineaBissau, se intenta ofrecer una perspectiva de la historia de África hacia las visiones de los africanos

Palabras-llave: Lucha de libertación nacional, Resistencias étnicas, Identidad guineana, Identidad étnica, Guinea-Bissau.

\section{INTRODUÇÃO}

Antes de discorrer sobre os processos de resistências na Guiné que engendrou a luta armada de libertação nacional e a construção do estado nacional, preciso salientar que não se trata de um estudo completo e abrangente da história das resistências na Guiné. Tratamos aqui de construir balizas para visibilizar a rica tradição de resistência dos povos da Guiné, que na visão eurocêntrica é desdenhado pela historiografia colonial.

Também não é do meu interesse nesse trabalho, fazer uma análise detalhada de todos os grupos étnicos envolvidos nos processos de resistên-

1 Doutoranda em Ciências Sociais pela Universidade Federal da Bahia - UFBA. Endereço eletrônico: pretadeguinebissau@yahoo.com.br. 
cias na Guiné, visto que seria outro estudo a parte, entretanto, farei análises de alguns grupos específicos que tiveram uma contribuição mais expressiva na tradição das resistências étnicas que possibilitarão a compreensão das funcionalidades políticas das campanhas de "pacificação" desencadeado pelo regime colonial, como também da gênese dos movimentos contestatórios que engendraram a luta de libertação nacional e a construção do estado nacional.

Considerada um mosaico étnico e cultural devido a sua rica composição étnica, a Guiné-Bissau é um país situado na costa ocidental do continente africano, limitado entre as duas Repúblicas: ao norte pelo Senegal e ao sul pela Guiné-Konakry, com superfície total de $36.125 \mathrm{~km} 2$.

O país é integrado ainda por cerca de quarenta ilhas que constituem o arquipélago dos Bijagós, separado do continente pelos canais de Geba, Bolama e Canhabaque. Além dos territórios continentais, que compreende oito regiões: Bolama, Báfata, Gabú, Cacheu, Biombo, Oio, Quinará e Tombali, mais setor autônomo de Bissau que é a capital. O clima é quente e úmido, caracterizado como subguineano. Trata-se de um clima favorável para a prática de agricultura e a pesca que se constituem nas principais fontes de subsistência para a população.

Segundo os dados estatísticos de 2009, a população guineense corresponde a um total de 1.548 .159 mil de habitantes. Tem uma densidade de 33,22 habitantes por $\mathrm{km}^{2}$, pois a grande maioria da população reside em zonas rurais. A Guiné-Bissau conta com mais de trinta etnias ${ }^{2}$, sendo dividas entre os grupos majoritários do país. O país se configura em cinco grandes grupos étnicos espalhados em diferentes regiões do país, compondo o seguinte cenário: Balantas (27\%), fulas (22\%), Mandingas (12\%), Manjacos (11\%) e Papeis (10\%), e outros $18 \%$ (cf. LOPES, 1982).

Vale resasaltar que a tradição cultural destes grupos étnicos é bastante rica e diversificada, enfatizada através das diferenças lingüísticas e das expressões artísticas entre outras categorias de análise.

2 Entendo etnia como uma unidade tradicional de consciência de grupo que se diferencia de outros pelo fato de partilhar laços comuns de território, cultura, valores, raça ou tradição histórica.

224 Número temático: Literatura, cultura e memória negra. A Cor das Letras - UEFS, n. 12, 2011 


\section{IDENTIDADES ÉTNICAS E RESISTÊNCIAS AO COLONIALISMO NA GUINÉ PORTUGUESA}

Assim como em outras partes do continente africano, o século XV aproximadamente o ano de 1446 marca o início da chegada dos portugueses no território que viria mais tarde a ser Guiné-Bissau, pois o acesso a costa da Guiné, ou seja, Senegâmbia deu-se através da rota instituída pelo navegador Álvaro Fernandes.

Não obstante, na Guiné, a ocupação começou no norte do país a partir da cidade de Cacheu fundada em 1588, mas sob a regência de administração de arquipélago de Cabo-Verde ${ }^{3}$. As primeiras feitorias foram construídas nos cursos dos rios (São Domingos, Cacheu, Farim e Buba) já que inicialmente os portugueses não intencionavam a ocupação no interior do país.

Assim, em 1642, cidade de Cacheu torna desde então a capitania e principal referência dos portugueses para acesso ao resto do país, sendo Farim fundada em 1640, e a atual capital Bissau teve a sua ocupação em 1686.

Apesar dos rios e da costa dessa área terem sido uma das primeiras partes colonizadas pelos portugueses, o interior só foi explorado a partir do século XIX. A atual capital do país, Bissau, foi fundada em 1697, com intuito de servir de suporte para a fortificação militar e entreposto de tráfico negreiro, que mais tarde viria a ser elevada a cidade e a capital do país.

Importante ressaltar que a colonização efetiva do interior da atual Guiné-Bissau iniciou-se no final do século XIX. Os interesses portugueses na região foram negociados na Conferência de Berlim como contraponto as ambições francesas de criação de uma África Ocidental Francesa (PÉLISSIER, 1989, p. 232).

Neste sentido, depois das delimitações das fronteiras resultante dos acordos entre os portugueses e franceses em 1886, onde uma parte de território que pertencia a Guiné (Cassamanse e Ziguinchor) ficou sob tutela da França, a Guiné foi conferido em 1879 como uma província independen-

3 Em 1834, pela aplicação da nova organização administrativa portuguesa de 1832, que suprimia teoricamente toda a distinção entre a Metrópole e as colônias, Cabo - verde e a Guiné passaram a formar uma prefeitura, na qual a Guiné era uma circunscrição dirigida por um subprefeito. Em 1836, foi criado um governo geral das ilhas de Cabo -verde no qual a Guiné passou a ser um distrito, comandado por um Governador. Em 1869, a Guiné foi subdividida em quatro comunas, Cacheu, Bissau, Bolama e Buba. O Governador residia em Geba (PAIGC, 1974, p. 96). 
te, sendo desvinculada da subordinação administrativa de Cabo-verde. Nesse ensejo, a aprovação do Estatuto da Província da Guiné em 1950, veio a consolidar o país como uma Província ultramarina.

Diante disso, é importante ressaltar que, por muito tempo, a GuinéBissau era reconhecida prioritariamente como Guiné Portuguesa, isto é, o território que participava do Ultra-Mar português, sinalizando assim o pertencimento a colônia portuguesa, ou seja, em 1951 a Guiné Portuguesa foi declarada província do Ultra-mar, governada diretamente por funcionários portugueses. Desta forma, o país passou a se chamar de Guiné Portuguesa, sendo considerada colônia exclusivamente de Portugal.

A região que hoje denominamos de Guiné-Bissau, nem sempre foi o mesmo território da chamada Costa da Guiné ou Costa Africana, ou melhor, Senegâmbia, pois a divisão arbitrária da conferência de Berlim em 18841885 traçou fronteiras e separou povos sem levar em conta as tradições culturais dos grupos étnicos existentes e suas fronteiras, obedecendo, portanto somente aos interesses coloniais.

E são esses limites territoriais estabelecidos nesta conferência que ainda perduram na delimitação geográfica na contemporaneidade nos diversos países do continente africano. Com efeito, na partilha territorial de África aconteceram casos em que um mesmo povo ou comunidade era dividido em vários subgrupos de acordo com números de candidatos europeus, sem se quer atentar para as diferenças culturais dos povos, como também das organizações políticas e sociais existentes, marcadas por hostilidades, que tornavam difíceis suas adaptações às estruturas políticas e administrativas coloniais.

Mas o que seria Guiné na época do tráfico, diferente da atual GuinéBissau ou Guiné Conakry ou Golfo da Guiné? Portanto, Guiné, Guinauha ou Gnawa, era o termo em usado para designar "terras de pretos", derivada de palavra berbesca Guinéus, que significava negro (LEMOS, 1996).

Assim, a Guiné na concepção dos portugueses foi ganhando codinome devido o trânsito comercial que se estabelecia na época, ora como costa de escravos, costa de ouro, costa de malagueta, costa de marfim, sendo classificada consoante a predominância de produtos comercias que se vendia.

Por fim, quando da ocupação efetiva foi denominado de Guiné Portuguesa, isto é sob regência da administração do estado colonial português e que mais tarde depois da independência em 1973 denominado oficialmente de Guiné-Bissau. 
Desde a chegada dos portugueses na Guiné no século XV, em 1446, objetivando inicialmente estabelecer trocas comerciais e constituir relações "amigáveis" com os chamados "desdenhosamente por eles de gentios", intermediados por alguns chefes locais, até a sua "partida forçosa" em 1973, ano em que a Guiné portuguesa passa a ser reconhecido pelo mundo afora como República da Guiné-Bissau, exaltando a soberania conquistada durante uma década de árdua luta de libertação nacional, foram relações recheadas de injurias, humilhações e submissões e revoltas entre as partes.

Durante esse período de aproximadamente cinco séculos (1446 a 1974), os habitantes da Guiné travaram sangrentas lutas de resistências contra os colonialistas portugueses que oscilava entre as questões inerentes a submissão de pagamento de impostos, ao cultivo forçado de colheitas de exportação, trabalhos forçados, serviço militar, obediência as autoridades portuguesa, etc. e até a obtenção da liberdade, soberania e independência.

Não obstante, os processos de resistências foram relativamente tardios e dispersos, moldados pelas reações individuais, isoladas e fragmentadas de todos os grupos étnicos que ora gravitava entre a revolta aberta e a resistência passiva.

Vários chefes locais se aliaram ao colonialismo e recusaram a participação nos processos de resistências por acreditarem em benefícios deste no apoio para a consolidação no poder nos seus Estados e outros privilégios que poderiam usufruir, não obstante assim que os portugueses colonialistas se sentiram avigorados, estes chefes se tornaram seus reféns.

Neste sentido, "os chefes africanos dificilmente se aperceberam de que os "tratados de amizade" que assinaram poderiam arruinar a sua independência e soberania" (MENDY, 1994, p. 43). Estes tratados com alguns chefes locais faziam parte das estratégias utilizadas pelos portugueses para consolidação da ocupação efetiva, além de estimular as rivalidades entre os grupos étnicos. Ou seja, "o colonialismo português esforça-se por alimentar a desconfiança e o ódio , cultivando os privilégios de casta, o regionalismo, o racismo, para melhor dominar e de explorar todos os africanos" (PAIGC, 1974, p. 53).

4 Trata-se dos indígenas, ou seja, aqueles que na concepção colonial não são civilizados, por não saber ler, escrever e falar português. Podemos dizer por outro lado, que são aqueles guineenses agarrados as suas tradições étnicas e se orgulham de ser povos tradicionais. 
Desta forma, as resistências intensificaram quando os colonialistas instituíram o imposto de palhota a todas as regiões da Guiné dita Portuguesa, que entrará em vigor a partir do janeiro de 1904 na tentativa de consolidar o domínio da ocupação.

Para facilitar a cobrança deste imposto, os portugueses contaram mais uma vez com o apoio dos chefes locais (seus aliados) e os régulos que serão isentados de pagamento de imposto de palhota, e ainda ganhariam por serviços prestados. Importante dizer, que o imposto de palhota era aplicado sobre habitações dos indígenas.

[...] o recenseamento para o imposto de palhota implicava a recolha de informação estatística vital acerca da população indígena, que estava dividida em seis categorias, por idades, além de sexo e estado civil. A informação era importante não só para fins fiscais, mas também para outras coisas, como por exemplo, trabalho forçado e serviço militar (MENDY, 1994, p. 405).

As primeiras reações foram várias, contra os abusos na recolha de impostos e a imposição de trabalhos forçados. Algumas etnias a exemplo dos Fulas e Mandingas que devido a extensão das famílias que possuíam cada chefe de família habitava numa casa própria separada dos demais na mesma tabanka, apesar de pertencerem um conjunto de linhagem,devido a cobrança de imposto de palhota passaram a coabitar com os parentes numa mesma casa, evitando o pagamento das taxas. Isto, entre outras estratégias, faz parte das resistências desenhadas pelos nativos para enfrentar a redução do numero de palhotas.

Os Manjacos, Mancanhas, Felupes, dentre outros, optaram por emigração para territórios vizinhos de Casamanse (Senegal) para dar continuidade ao cultivo dos produtos que eram taxados na Guiné Portuguesa, dentre outras estratégias traçadas pelos grupos étnicos a fim de bloquear o imposto de palhota. Estas foram às primeiras reações denominadas de resistências primárias.

As formulações de Peter Karibe Mendy (1992) descreve a intenção desesperada dos portugueses depois da Conferencia de Berlim, ou seja em 1886 depois da fixação das fronteiras da Guiné portuguesa, de consolidar a Guiné portuguesa, contudo não havia concretizado uma ocupação efetiva do território.

Da Guiné chamada portuguesa só existia apenas o nome formal. Não existia o reconhecimento e legitimidade da soberania portuguesa, é nesse ensejo que os portugueses ao instituíram o novo imposto de palhota em 1903, apostaram no restabelecimento da soberania, a submissão dos nati- 
vos e a exclusividade do território. Contudo, as reações dos habitantes da Guiné desafiaram as autoridades portuguesas e as resistências foram intransigentes com todas as etnias quando da tentativa de aplicação do imposto como citado acima.

Vale salientar que na Guiné as resistências tiveram características regionais e étnicas, devido a configuração social do país, teoricamente cada grupo étnico pertence a um "chão" (terra). Neste sentido é recorrente as dispersões das "guerras" regionais desencadeadas por cada grupo étnico durante os processos de resistências, contudo a divisão não se limitava apenas ao espaço geográfico mas também as tradições culturais destas etnias, ou seja, as formas de organização social e cultural de cada sociedade.

É nesse cenário de divisão do espaço geográfico étnico que as primeiras expedições portuguesas foram desencadeadas em 1886 contra os Balantas, os Beafadas e os Oincas, caracteristicamente identificados como habitantes do litoral do país, que veio a terminar em 1897. Em seguida foi com os papéis da Ilha de Bissau em 1900, e mais tarde com os Bijagós de Formosa em 1906. Importante, salientar que a intensificação definitiva das campanhas de "pacificação" será efetuada a partir de 1913 a 1936 comandado pelo Estado-maior da Colônia, o sanguinário, Capitão Teixeira Pinto ${ }^{5}$.

Teixeira Pinto comandou as expedições contra os nativos na Guiné, elegendo como principais aliados os grumetes e o Abdul Injai ${ }^{6}$ cuja função será de intermediação entre as autoridades coloniais e os habitantes locais. Desta forma, para melhor reconhecimento das regiões, Teixeira Pinto realizou primeiro um estudo minucioso que objetivava o mapeamento das regiões critica de expedições e o contacto com algumas regiões disfarçando de

5 João Teixeira Pinto, natural de Angola, era neto de um oficial de exercito português, graduou-se na academia militar em Portugal, regressou a Angola em 1902, onde participou numa quantidade de operações contra os indígenas rebeldes, obtendo o almejado titulo de Kurika, a mais elevada condecoração por mérito militar. Em setembro de 1912 desembarcou em Bolama (Guiné-Bissau) onde foi nomeado chefe do Estado-Maior a fim de comandar as campanhas de pacificação contra os indígenas promovendo o estabelecimento da soberania portuguesa na Guiné (MENDY, 1994, p. 218).

Tratava-se de um fugitivo senegalês que residia na Guiné. Considerado homem valente, cruel e de sangue frio, era temido pela sua hostilidade, também considerado como braço direito de Capitão Teixeira Pinto. Os estudos de Peter Karibe Mendy (1994, p. 250) ressaltam que Addul Injai e o seu bando de mercenários, desempenharam o papel importante nas campanhas de pacificação que possibilitaram a tão celebradas vitorias portuguesas. A utilização da sua quadrilha de bandidos como tropas de choque foi decisiva para quebrar a determinação dos insubmissos. 
contabilista de casa de comércio francesa, a fim de espreitar os nativos temidos pelas autoridades portuguesas possibilitando a organização dos ataques contra os revoltados.

Nessa conjuntura, cotejando a cronologia histórica, podemos classificar os processos de resistências em duas etapas: a primeira são as resistências étnicas, denominadas de "pacificação" ou "resistências primárias" comandadas por alguns segmentos étnicos contra a ocupação portuguesa entre 1913 a 1936. As chamadas "resistências secundárias" teve seu marco a partir do ano de 1952, quando as primeiras organizações urbanas clandestinas surgiram lideradas pela elite intelectual local contra a administração portuguesa.

Em linhas gerais, o que impulsionou tais resistências foi a destituição do poder aos africanos, os abusos excessivos e a imposição cultural, como também a falta da liberdade, a soberania e a independência. Importante ressaltar que a pressão a dominação colonial não cessou com o término das campanhas de "pacificação", muito pelo contrário, ganhou um contorno político ideológico com os movimentos nacionalistas para a contestação das independências.

Apesar de todas as resistências organizadas por grupos étnicos, a violência dos portugueses foi ganhando maiores proporções. Os colonialistas portugueses aliaram a ocupação não só à repressão como também o racismo, a perseguição das crenças, a tortura, massacres, mortes, recursos utilizados como forma de intimidar os nativos no que refere os levantes e a resistência contra a imposição colonial. Essas revoltas dos povos nativos não só exprimiram de um lado o ódio do povo em relação à dominação portuguesa no tocante a recusa total de pagamentos excessivos de impostos e da soberania portuguesa, como também por outro forjou a conscientização da unidade para luta de libertação nacional.

Essas reivindicações contra o sistema colonial representados pelos distintos grupos étnicos do país objetivavam a lutar contra a opressão e o restabelecimento da liberdade, neste sentido não tinha características de movimentos de contestação para a independência e autonomia política.

\section{MOVIMENTOS CONTESTATÓRIOS PARA INDEPENDÊNCIA E A CRIAÇÃO DA CONSCIÊNCIA NACIONAL}

A assertiva de Amilcar Cabral (1980) e Peter Karibe Mendy (1994) de que a tradição da resistência do povo da Guiné não teve término com a guerra contra os indígenas nas campanhas de "pacificações", é um ponto 230 Número temático: Literatura, cultura e memória negra. A Cor das Letras - UEFS, n. 12, 2011 
inicial para analisar as organizações políticas urbanas de cunho nacionalistas criadas pelos filhos da terra com intuito de prosseguir as reivindicações contra a submissão á dominação estrangeira. Assim como a primeira onda de resistência veio a reforçar a segunda, dando forma a contestação definitiva de que serviria não apenas para a liberdade e autonomia, mas sim para a conquista total da independência.

Foram os indivíduos hierarquicamente denominados como assimilados (civilizados, grumetes, mestiços, funcionários administrativos e pequenos comerciantes, entre outros privilegiados pelo colonialismo português que colaboravam direta ou indiretamente com o empreendimento colonial) que na Guiné portuguesa reivindicaram não só contra a estrutura colonial português no tocante a integração e a participação na sociedade e política colonial, como também protestaram dos abusos e injustiças, contestando a independência política pois ansiavam também a participação no poder do seu país.

É nesse cenário que proliferam os movimentos urbanos de contestação para a independência política e econômica na Guiné portuguesa, as denominadas resistências secundárias nos anos de 1952. Vale ressaltar que todos estes movimentos comungavam de uma característica: conquista da autonomia política e a independência total.

Analisando com cuidado a tese da contestação política destes movimentos, cabe indagar: a quem interessava a independência na Guiné? Em resposta localizamos os interesses de uma elite intelectual guineense buscando participar do exercício do poder na sua terra. Essa elite organizou vários movimentos clandestinos à partir da década de 50 do século XX para pensar o projeto da nação e promover a articulação política (tanto a nível interno quanto externo) para garantir a legitimidade das ações contra a ocupação portuguesa.

A estas organizações - que denominamos de resistências secundárias - rubricadas pelas elites urbanas coube a responsabilidade de culminar com a luta armada de libertação nacional em 1963. Tais grupos eram caracterizados em forma de associações de bairro, clubes desportivos, dirigidos pelos assimilados e intelectuais que eram funcionários das grandes casas comerciais coloniais (Casa Gouveia, Banco Ultramarino entre outros) que reivindicavam dos seus patrões ações contra o racismo e a discriminação racial no serviço público colonial, o trabalho forçado, más condições de trabalho, salários baixos, a falta de educação para os nativos e o reconhecimento e liberdade para os povos da Guiné. 
É a partir desse período do pós-guerra no ano de 1945, que as reivindicações de cunho nacionalistas proliferaram na Guiné representados sob várias organizações sinalizando o inicio dos movimentos "protonacionalistas ou nacionalismo incipiente".

A questão central que está na base da origem do nacionalismo não só de Guiné, como também em Angola, Moçambique, Cabo-Verde e São Tomé e príncipe, deve-se excepcionalmente a política assimilacionista portuguesa que ambicionava formar culturalmente e politicamente um grupo de indivíduos que estabeleceriam uma relação de lealdade com o governo português, isto é, africanos que seriam intermediários entre o sistema colonial e comunidades locais, objetivando assim a consolidação do domínio português nos territórios africanos.

Não obstante dentre todas as colônias portuguesa em domínio, a Guiné desempenhava pouca importância no quadro da administração não só pelo fato de houver grandes resistências étnicas que impossibilitaram inicialmente a efetivação do domínio, como também não podemos perder de vista que a cidade de Bissau apesar de inicialmente apresentar condições favoráveis por dispor de rios navegáveis, que facilitava a aproximação com as regiões vizinhas, entretanto na concepção dos portugueses era precária em todos os sentidos principalmente no que refere a estrutura urbana, sem condições mínimas de sobrevivência, não tinha estradas, e o fornecimento da e energia elétrica se limitava aos bairros dos civilizados, enfim, faltava de tudo um pouco na cidade, principalmente nos bairros dos indígenas.

Por outro lado, Bissau era considerada um lugar pouco favorável para a sua permanência no tocante ao desenvolvimento de certas doenças tropicais, tais como febre amarela, paludismo (malária) dentre outros. Com isto Bissau passaria prioritariamente a ocupar o lugar de residência temporária para os portugueses para o desenvolvimento do comércio, já que o território apresenta uma infinita riqueza para a prática de agricultura.

As formulações de Maria Manuela veio corroborar o estado de subalternização a que era atribuída a cidade de Bissau em relação as outras colônias portuguesas durante a administração colonial. Segundo a autora,

Angola e Moçambique foram, desde a independência do Brasil, as duas grandes colônias portuguesas de África, às quais a metrópole votava a maior atenção ao passo que a Guiné ocupava, desde o início, um lugar pouco importante. Era a única que dependia exclusivamente dos capitais da metrópole e tinha uma condição subalterna resultante da sua união com Cabo Verde. Pesava sobre ela a má reputação da insalubridade e do paludismo, por isso mesmo tinha sido apenas, até aí, um mercado bem abastecido de escravos. 
As condições climáticas eram consideradas pouco propícias à fixação dos europeus. Quanto às gentes, era costume afirmar-se serem as mais desvairadas e rebeldes e possuírem costumes bizarros. Por isso, era essencialmente a ralé do Reino que ali se fixava vivendo em palhotas miseráveis, fazendo comércio e pagando impostos aos chefes indígenas (LUCAS apud FRANCO, 2009, p. 40).

Com efeito, mesmo com as condições climáticas pouco propicias alegadas para a fixação no país, as autoridades coloniais portuguesas criaram divisões no país, ostentaram racismos sem receios e concedeu privilégios aqueles que a todo custo tentavam imitar e reproduzir a cultura portuguesa.

Assim, a cidade de Bissau estava hierarquizada entre os que sabiam ler e escrever, ou seja, os civilizados, e os indígenas aqueles que não se socializavam com o costume português, isto é, não eram cristons e nem tinham domínio na língua portuguesa. Importante dizer que, os cristons eram os indivíduos de ascendência africana, que adotaram a religião católica e a língua portuguesa como categoria de uma identidade social européia. Neste sentido, a cidade de Bissau nos finais de século XIX e inicio de século XX estava caracterizado pelo sentimento exacerbado de pertença de castas, linhagens e grupos étnicos. Assim sendo,

\begin{abstract}
em termos de estratificação social, a Guiné colonial da segunda metade do século XIX caracterizava-se por linhas de clivagem em volta de várias camadas sociais, entre as quais se destacavam os mulatos (descendentes de um europeu e de uma africana) e os mestiços (de mãe guineense e de pai cabo-verdiano). Estes grupos preferiam em geral a cultura europeia e o cristianismo. Muitos oriundos de Cabo Verde ocupavam o topo da pirâmide e formavam o núcleo dos designados por creoulos, outra expressão para designar os descendentes do cruzamento de europeus e africanos ou de qualquer outra mestiçagem baseada em origens socioculturais diversas. A seguir vinham os africanos cristãos ou gurmetos, de pura ascendência africana. O denominador comum que os unia era o facto de todos reclamarem a africanidade, uma identidade social contraposta à identidade social europeia (CARDOSO, 2008, p. 8).
\end{abstract}

Nesse contexto, era natural a divisão dos centros de socialização entre estes segmentos, pois havia espaços que era prioritariamente dominado pela elite branca e os cristons de praça (os residentes na zona urbana), a exemplo de UDIB (União Desportiva Internacional de Bissau) e Benfica também uma agremiação esportiva dos portugueses, além de clubes dos caboverdianos.

Como referido acima, na década de 50 , surgiram vários movimentos clandestinos de cunho político que objetivava contestar a independência. 
Desta maneira, foram criadas as primeiras organizações com caráter partidário, a exemplo do MLGC (Movimento de Libertação da Guiné e Caboverde). Depois seguia a UPG (União de Povos da Guiné fundada pelo caboverdiano Henri Labery), o RDAG (Reunião Democrática Africana da Guiné), a UNGP (União dos Naturais da Guiné Portuguesa), a UPLG (União da População Libertada da Guiné), que agrupava a minoria de etnia Fula do Senegal, e o MLG (Movimento de Libertação da Guiné fundada em 1958) que agregava a maioria da etnia manjaca da Guiné, o MING (Movimento para a Independência da Guiné, fundada em 1954 criado por José Francisco e Luís António da Silva, "Tchalobé), PAI (Partido Africano para Independência, que mais tarde daria origem ao PAIGC_fundada em 1956, já por iniciativa de Amílcar Cabral, e os seus compatriotas cabo-verdianos e guineenses: Luís Cabral, Aristides Pereira, Elisée Turpin, Abílio Duarte, Júlio de Almeida e Fernando Fortes), e por fim FLING (Frente de Libertação Nacional da Guiné_fundada em 1962) dirigida por Labery, Pinto Bull e François Kankola Mendy, que seria resultante da unidade partidária entre o UPG, o RDAG e a UPLG. (GARCIA, 2000).

Neste universo de representações políticas vale destacar que só o PAIGC conseguiu a hegemonia política para dirigir a luta de libertação nacional, como havia analisado no primeiro capitulo.Portanto, a resistência cultural e política contra a ocupação portuguesa na Guiné foi representado pelo o movimento de libertação nacional liderado pelo Amilcar Cabral engendrando a unificação de todas as etnias dentro das fronteiras, sem distinção cultural num programa de "consciência nacional" para a liquidação do colonialismo, criando assim uma contra-sociedade à sociedade colonial.

Depois do massacre de Pindjiguiti ${ }^{7}$, a elite intelectual reconfigurou as estratégias junto às massas populares. Desse modo, surgiu a necessidade de uma organização mais consistente para enfrentar a administração colonial: a luta armada. Para Amilcar Cabral (1974, p. 57-58), a luta armada constitui a única via para libertação do povo guineense da opressão. Por ele afirmou que:

Nessa altura, o nosso Partido decidiu realizar uma conferência clandestina em Bissau e foi então que mudamos de orientação. Quer dizer, começamos a

7 O massacre de Pindjiguiti, de três de agosto 1959, constitui marco da repressão violenta que a administração colonial executou contra os marinheiros e estivadores no cais de Pindjiguiti, devido a uma grave organizada por estes com intuito de reivindicar melhores condições de salário. Dos estudos depreendem que, foram assassinadas mais de cinqüenta marinheiros pelos militares e os civis portugueses.

234 Número temático: Literatura, cultura e memória negra. A Cor das Letras - UEFS, n. 12, 2011 
mobilizar os campos e decidimos preparar-nos ativamente para a luta armada contra as forças colonialistas portugueses. Decidimos que as massas populares não deviam fazer nenhuma manifestação que pudesse dar lugar a represálias criminosas da parte dos colonialistas portugueses.

Para Amilcar Cabral, o partido traçou prioridades centradas em duas fases em seu programa de luta: primeiro a libertação que daria seguimento a construção de uma nova sociedade, sendo que a luta da libertação seria contra todas as formas de exploração do homem pelo homem, do racismo e do sistema colonial, além da concessão total da independência da Guiné e Cabo-Verde.

Convém ressaltar que toda a estratégia para a mobilização para a luta traçada pela elite intelectual guineense objetivava ressaltar a importância das tradições culturais locais, como fator principal da viabilização da luta armada.

Não obstante a luta da libertação nacional, também é uma luta cultural da preservação da cultura e da recusa de adoção a nova cultura. Desta maneira, a recusa da imposição do domínio cultural europeu, incentivou por um lado a convivência e trocas de experiências culturais diferentes entre as etnias guineenses, ao tempo que forjou um projeto comum: a cultura de libertação nacional. Isto também está documentado por Davidson (1976, p. 40):

[...] a participação das massas passa a significar a ativa integração individual em comitês políticos eleitos e a aceitação das numerosas responsabilidades decorrentes do esforço para construir, nas áreas libertadas, novas estruturas para uma nova sociedade. É por isso que estes movimentos se tornaram revolucionários.

As sucessivas ondas de repressões por parte da administração portuguesa forjou uma maior conscientização das massas populares para ingressarem nas fileiras da luta armada como forma de se opor ao sistema opressor português. Contrário do que vinha acontecendo, os portugueses começaram a perder apoio de alguns segmentos étnicos no país devido às excessivas taxas de impostos e conseqüentemente o não cumprimento das promessas, como atesta Cabral (1974, p. 21):

[...] a situação política é, portanto cada vez mais tensa. A Guiné vive (hoje) em estado de sitio, estando todos os colonos armados e as populações autóctones submetidas a provocações freqüentes da parte dos militares e da policia colonial. Para fazer face á maré crescente da nossa luta de libertação, os colonialistas portugueses reforçam continuamente o exército. 
A partir de 1959, houve uma participação expressiva das massas populares afiliados ao PAIGC, o que possibilitou desencadear a luta armada em 1963. Entretanto, o partido contava com alto índice de analfabetismo no seio dos seus membros, e tinha que suprir esse quadro crítico de forma que traçou planos de cursos de alfabetização e formação para estes membros. É também Cabral (1974, p. 61) que declara:

[...] fazemos a guerra não porque sejamos guerreiros ou porque gostamos da guerra. Não fazemos a guerra para conquistar Portugal. Fizemo-la porque somos obrigados a isso para conquistar os nossos direitos humanos, os nossos direitos de nação, de povo africano que quer a sua independência mas o objetivo da nossa guerra é um objetivo político, isto é, a libertação total do nosso povo da Guiné e de Cabo Verde, a conquista da nossa independência nacional e da nossa soberania tanto interna como no plano internacional.

Contudo, a luta armada, não se constituía a priori a preferência da elite local, mas era a única via para obtenção da independência perante o sistema opressor português. Visto que todos os planos traçados a fim de pressionar a retirada dos portugueses no país, através de greves, manifestações civis, etc., foram sem sucesso, isto é, todo o esforço empenhado na pressão pacifica terem redundado apenas em maior pressão por parte da administração colonial. Neste sentido Amilcar Cabral (1974, p. 61) afirma:

[...] fazemos a guerra não porque sejamos guerreiros ou porque gostamos da guerra. Não fazemos a guerra para conquistar Portugal. Fizemo-la porque somos obrigados a isso para conquistar os nossos direitos humanos, os nossos direitos de nação, de povo africano que quer a sua independência, mas o objetivo da nossa guerra é um objetivo político, isto é, a libertação total do nosso povo da Guiné e de Cabo Verde, a conquista da nossa independência nacional e da nossa soberania tanto interna como no plano internacional.

Assim sendo, foram forçados a aderirem a via armada como forma de impor a legitimidade e reconhecimento da independência e da soberania. Como citado anteriormente, o ano de 1963, marca o início da luta armada em áreas rurais, tanto no centro do país como no sul e no norte do país, demarcando territórios que mais tarde viriam se chamar de zonas libertadas.

Essas zonas libertadas se configuravam como um estado guineense, dentro do estado colonial, promovendo políticas públicas de inclusão que contemple os membros do partido através de construção de escolas para formação de quadros políticos, postos médicos, entre outras instâncias de organização. 


\section{CONSIDERAÇÕES FINAIS}

É sabido o quanto os africanos lutaram para a obtenção da liberdade e autonomia, articulando várias estratégias de resistências contra o colonialismo. O colonialismo por sua vez, semeou e fomentou conflitos entre os habitantes locais, criou hierarquias sociais, concedendo privilégios a certos grupos étnicos em detrimento de outros, com intuito de criar dissenso entre os africanos e desarticular o projeto de unidade para construção do estado-nação.

O projeto de estado nacional na Guiné-Bissau foi alicerçado pelo Amilcar Cabral através da Luta de libertação nacional engendrando a unidade entre dois países (Guiné e Cabo-Verde), numa luta e numa independência. Foi no contexto da invasão européia, concretamente pelos portugueses é que surgiu as iniciativas espontâneas para criação de diversas organizações de cunho partidária, para contestação do sistema colonial português.

No cenário de várias representações políticas, o PAIGC o partido liderado por Amilcar Cabral conquistou a legitimidade para a condução da luta armada em 1963 depois de disputas políticas entre outras organizações políticas. A luta armada edificou o estado nacional como uma representação política de soberania e autonomia política. Foi um processo árduo que teve a duração de onze anos, tendo seu termino em 1973 com a proclamação unilateral da independência da Guiné nas zonas libertadas do país.

\section{REFERÊNCIAS}

ANDRADE, Mário de. A guerra dos povos na Guiné-Bissau. Lisboa: Livraria Sá Da Costa Ed., $1974 / 1975$.

CABRAL, Amilcar. A arma da teoria (Carlos Comitini). Rio de Janeiro: Codecri, 1980, cap. 4. Col. Terceiro Mundo, v. 4.

CABRAL, Amilcar. Guiné-Bissau, nação africana forjada na luta. Lisboa: Publicações Nova Aurora, 1974.

CARDOSO, Carlos. Sociedade civil, espaço público e gestão de conflitos: o caso da GuinéBissau. Texto apresentado na 12 2 Conferencia geral de CODESRIA em Yaoundé, Cameroun 2008.

DAVIDSON, Basil. A política da luta armada. Libertação nacional nas colônias africanas de Portugal. Lisboa: Editorial Caminho, SARL, 1976.

FRANCO, Paulo Fernando Campbell. Amilcar Cabral: a palavra falada e a palavra vivida. Dissertação de mestrado. São Paulo: Universidade de São Paulo, 2009. 
GARCIA, Francisco Proença. Guiné 1963-1974: os movimentos independentistas, o islão e o poder português. Lisboa: Universidade Portucalense Infante D. Henrique/Comissão de História militar, 2002.

LEMOS, Mário Matos. Os portugueses na Guiné-Bissau. Apontamento para uma Síntese. Lisboa: Ed. Crédito Predial Português, 1996.

LOPES, Carlos. Kaabunke: espaço território e poder na Guiné Bissau, Gâmbia e casamento pré colonial. Lisboa: Comissão Nacional para as Comemorações dos Descobrimentos Portugueses, 1999.

M’BOKOLO, Elikia. África negra história e civilizações. Do século XIX aos nossos dias, tomo II. São Paulo, Salvador: Casa das Áfricas, Edufba, 2011.

MALOWIST, Marion. A luta pelo comércio internacional e suas implicações para a África. In: História geral da África, V: África do século XVI ao XVIII. Editado por Bethwell Allan Ogot. Brasília: UNESCO, 2010.

MENDY, Peter Karibe. Colonialismo português em África: a transição de resistência na GuinéBissau (1879-1959). Lisboa: Instituto Nacional de Estudos e Pesquisa, cop. 1994. II.: Kacu Martel.

PAIGC. História da Guiné e Ilhas de Cabo-Verde. Porto: Ed. Afrontamento, 1974.

PÉLISSIER, René. História da Guiné: portugueses e africanos na Senegâmbia (1841-1936). Trad. Franco de Sousa. Lisboa: Estampa, 1989.

RIBEIRO, Carlos. A historicidade da construção nacional na Guiné-Bissau. In: Construção da nação em África: os exemplos de Angola, Cabo Verde, Guiné-Bissau, Moçambique e São Tomé Príncipe. Colóquio INEP/CODESRIA/UNITAR. Guiné-Bissau: INEP, 1989, p. 223-240.

SILVA. António E. Duarte. Invenção e construção da Guiné-Bissau. Lisboa: Almedina, 2010. Col. Estudos de Direito Africano. Tema: Direito Constitucional. 